\title{
Innovative Strategies For Teaching Principles Of Accounting And Federal Taxation Classes
}

Michael A. Seda, (E-mail: mseda@shawu.edu), Shaw University

\begin{abstract}
By integrating meaningful group learning experiences into my Principles of Accounting and Tax classes, Accounting was effectively promoted as an undergraduate major or minor, as supported by student satisfaction surveys. Many accounting programs are facing unprecedented challenges raised by declining enrollments and dynamic changes in profession. Using Baker, Simon, and Bazelli's (1985) Instructional Design for Accounting based on Kolb's Experiential Group Learning Model, multiple teaching strategies were incorporated into my classes appealing to multiple student learning styles and, as a result, student's attitude towards Accounting were significantly effected. The following is a brief list of group or solo activities used in my classes:

- $\quad$ Played Financial Accounting and Tax Jeopardy Games that are published on my website (www.geocities.com/docseda)

- $\quad$ Accounting students developed Excel-based Accounting Information System for service and merchandising businesses.

- $\quad$ Accounting students presented an analysis of an annual report.

- $\quad$ Accounting students played Stock Market Simulation Game (www. ncarolinasms.org).

- $\quad$ Accounting students played Monopoly.

- Accounting students played business simulation game at AICPA website (www. startheregoplaces.com).

- $\quad$ Tax students worked on three comprehensive tax returns prepared with TaxCut software.

- $\quad$ Selected Tax students took IRS exam to qualify for VITA program in spring of 2004.

- $\quad$ Accounting and Tax students prepared posters summarizing various concepts.
\end{abstract}

This article will provide a detailed summary of learning experiences used in the Fall Semester of 2003 at Shaw University and an analysis of student surveys.

\section{Introduction}

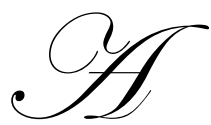

special report by the Accounting Education Change Commission (1990) called for a need to enhance students' teamwork, interpersonal and communication skills, and learning methods. Much of the response to the AECC's recommendations for change in accounting education has been directed toward curriculum reform. This type of response is troublesome given conclusions reported in Astin's (1993) national study of over 200 four-year colleges. He concludes that form and content of education curriculum makes little difference. What is most important is manner in which the curriculum is implemented. Thus, more emphasis is needed on pedagogy and delivery system. The implication for accounting educators is to be careful not to change merely content of course but to evaluate how that content is being delivered. The process of course delivery cannot only affect learning, but also student's choice of major. Many accounting programs are facing unprecedented challenges raised by declining enrollments and dynamic changes in profession. Based on proposed solutions by Barsky, Catanach, and Kozlowski (2003), the "best" teachers should be assigned to introductory or core courses to help promote accounting as a major or minor at undergraduate level. According to Barsky, Catanach, and 
Kozlowski (p.456) feedback in form of student satisfaction surveys is key to measuring relative "student market share." This idea suggests that department chairpersons should revisit how these courses are being taught, since these courses represent an excellent opportunity to interest students in accounting.

Baker, Simon, and Bazelli (1987) conducted a study to select and design an instructional design for optimal teaching mode (stimulus pattern sent to students) in area of accounting, which addresses content coverage and selfdevelopment. Baker, Simon, and Bazelli (p.216) stated that optimal teaching mode for accounting courses is based on Kolb's Experiential Group Learning Model, to be discussed shortly, since approach accommodates learning styles of all students while developing their communication, interpersonal, and reasoning skills.

\section{Kolb's Model of Experiential Group Learning}

Kolb's well-established experiential learning model (ELM) has attracted much interest and application. His model is founded on Jung's concept of types or styles through which the individual develops by using higher level integration and expression of non-dominant modes of dealing with the world (Kolb, 1984). Experience is translated into concepts that, in turn, guide the choice of new experiences (see Figure 1). Learning is conceived as a four-stage cycle starting with concrete experience, which forms the basis for observation and reflection on experiences. These reflective observations are then assimilated into abstract concepts and generalizations that guide new active experimentation experiences and interactions with the world. This model reflects two independent dimensions based on (a) perceiving, which involves concrete experience (feeling) and abstract conceptualization (thinking), and (b) processing, which involves active experimentation (doing) and reflective observation (watching). These two dimensions form the following four quadrants reflecting four learning styles (see Figure 2): accommodator, diverger, assimilator, and converger. Kolb (1985) described accommodators as learning by "hands-on" experiences and "gut" feelings rather than from logical analysis. Divergers are best at viewing concrete situations from many different points of view. Assimilators are best at understanding a wide range of information and putting it into a concise and logical form, and convergers are best at finding practical uses for ideas and theories. The effective learner can use each of the four styles in different learning situations rather than only relying on his or her dominant or preferred style. Students involved in heterogeneous group learning situations with an effective facilitator create an environment for maximum self-development.

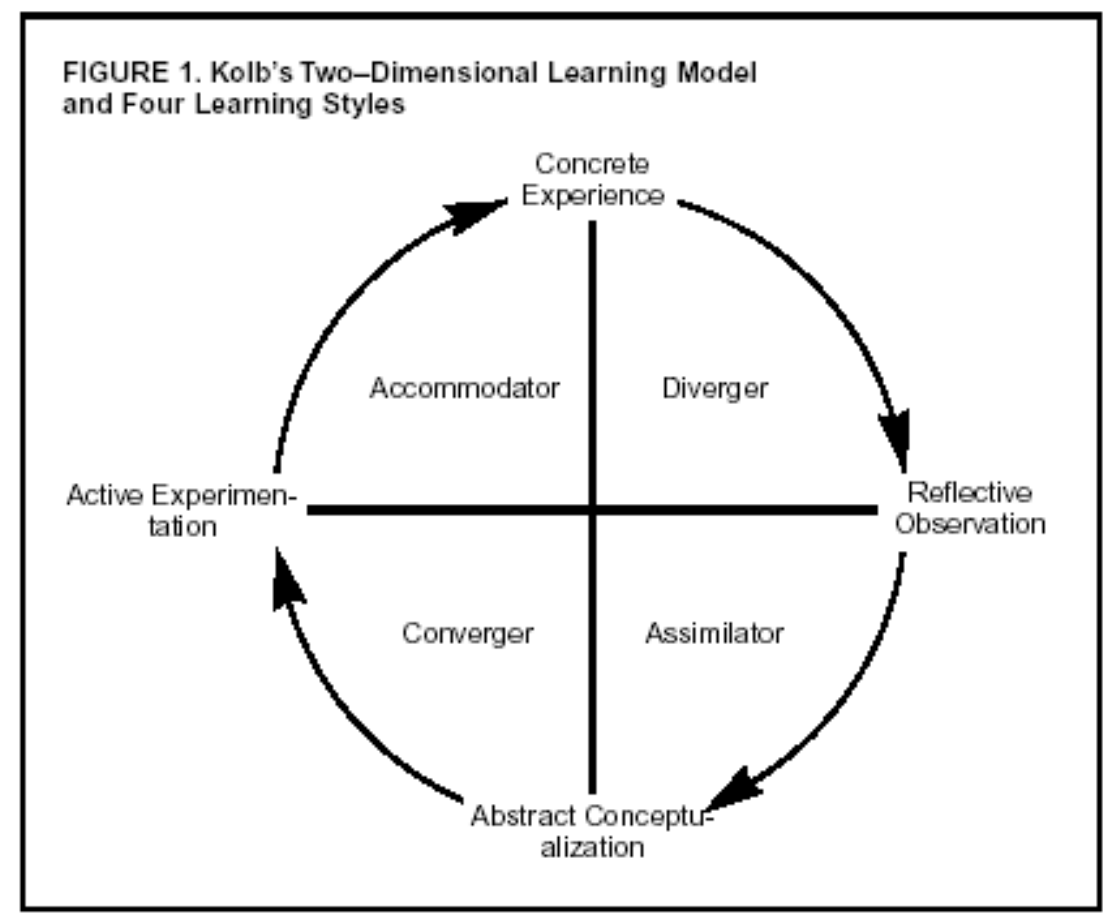


FIGURE 2. The Perceiving and Processing Dimensions and the Four Learning Types

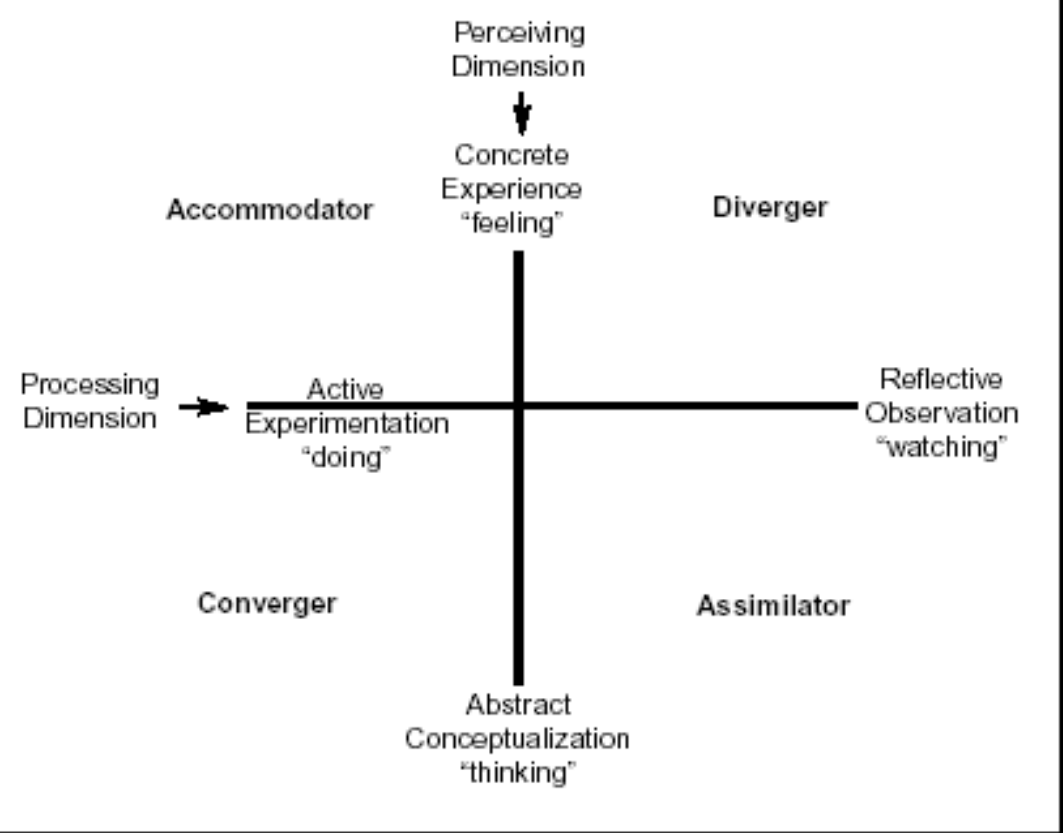

\section{Baker, Simon, and Bazelli's Instructional Design for Accounting based on ELM}

The following are six steps involved in Baker, Simon, and Bazelli's (1987, p.218) instructional design for Accounting based on Kolb's Experiential Group Learning Model (ELM):

\section{Step 1: Group Formation}

Large classes need to be divided into study groups of three to six students. Formation of groups can provide support for individual students who are having difficulty with a specific learning stage.

\section{Step 2: Concrete Experience (CE)}

During Concrete Experience stage of instructional cycle, purpose is to present students with samples of objects, artifacts, behaviors, processes, or phenomena found in practice.

\section{Step 3: Reflective Observation (RO)}

After students have observed samples of concepts, concepts are proved deductively, expanded, and added to related concepts. Instructional method in this stage is usually deductive lecture and discussion.

\section{Step 4: Abstract Conceptualization (AC)}

Students are now ready to enter theory-building and problem-testing stage of learning cycle. The most effective system of instruction is a problem solving lab environment.

\section{Step 5: Active Experimentation (AE):}

Learning process in this stage leads to application of what has been learned to practical problems encountered by practitioners. Role-play and simulation gaming are teaching methods used for this stage.

\section{Step 6: Evaluation:}

Evaluation instruments such as quizzes and tests are part of feedback mechanism that teacher uses to inform students 
of their progress in learning environment. The evaluative instruments should include a variety of questions that incorporate each level of Bloom's taxonomy of objectives (Knowledge, Comprehension, Application, Analysis, Synthesis, and Evaluation).

Accountants today are expected to be dynamic multi-perspective business advisors and hence a more dynamic multi-perspective instructional approach such as ELM should be adopted. Baker, Simon, and Bazelli (1987) state that since our post-secondary student population possesses varied learning styles, aptitudes, and attitudes, a multi-faceted instructional approach such as ELM is required in order to maximize students' academic performance as well as their self-development in terms of communication, interpersonal, and creative thinking skills. This teaching method supports the call by AECC (1990) to make students active participants in the learning process. Cottell and Millis (1993) stated that group learning is a shift towards learner-centered classrooms that foster student retention and better attitudes toward course content. My study will be undertaken to investigate feasibility of introducing experiential learning teaching method, as advanced by Kolb, in introductory accounting and tax classes in order to positively effect student's perception and knowledge of Accounting with ultimate goal of recruiting Accounting majors and minors.

\section{Purpose of the Study}

The purpose of this study will be to implement the ELM approach in Introductory Accounting and Tax courses, as designed by Baker, Simon, and Bazelli (1987), for select classes at Shaw University with the primary goal of positively changing student's attitude towards Accounting to the degree that they would consider an Accounting major or minor and secondly, to determine effect of group learning experiences on individual academic performance.

\section{Related Literature}

Astin (1993) states that the single most powerful influence on undergraduate academic and personal development is one's peer group. He further states that group learning is more powerful than traditional styles because it motivates students to be actively involved in the learning process. This mode of learning reflects a shift away from competition in the learning environment and into interdependence and mutuality. In his comprehensive study, Astin (1993) broadly defines peer group to include activities, such as group discussions of course content and group projects, as well as social interactions.

King (1992) asserts that a group-learning context provides individuals with conflicting viewpoints on a topic. By attempting to understand each other's ideas, the group members restructure their own knowledge. Through explaining and defending their views, conflicts are reconciled. The end result is an opportunity for individual students to observe the reasoning, logic and decision-making and problem-solving behaviors of other group members.

Stuart and Rutherford (1976) stated that even if lectures were used to first present all of the content information, research shows that student concentration--even among medical students--declined after 10 to 15 minutes. McKeachie et al. (1987) reviewed numerous studies that compared lecture with discussion classes. Retention and motivation for further learning were both higher with the discussion methods. Fraser et al. (1977) found that students working in groups of two, three or four led to higher course grades for those in the groups than for those working alone. Little evidence exists for accounting classes, but in 1984, Fiechtner and Davis (1992) surveyed business school students. They found that only $9.4 \%$ of the surveyed accounting classes had experienced any group work. Moreover, $18.7 \%$ of the business students indicated that their "least positive" group experiences had been in accounting. This was the highest percentage of "least positive" group experiences reported for any course. When asked what courses had "most positive" group experiences, no one indicated that it was an accounting course.

Ravenscroft et al. (1993) examined the effect of having part of one's course grade determined by the performance of every member in one's assigned study group. In a Principles of Accounting I class, individual 
student performance was higher as a result of the assigned groups. However, the results did not hold true for an auditing class. Thus, what types of group exercises work best in various contexts need to be explored.

Like other researchers (Collins \& Milliron, 1987; Drew \& Ottewell, 1998; Kolb, 1984), Loo (2002) recommended in his study that educators encourage students to use all four learning styles appropriately. Rather than relying on a preferred style, students should use a wide range of learning methods. There appears to be substantial benefits to students who develop the ability to adopt different learning styles in different situations, recognize their own learning strengths and preferences, and approach learning situations with flexibility.

Hite (1996) in a study involving over 250 students enrolled in individual income tax classes showed that final exam scores for those who participated in group exams were significantly higher than the scores for those who only took individual exams over the same material. Moreover, responses on student evaluations indicated that group exam students were significantly more likely to believe the course was mentally challenging, the teacher was fair and impartial, and the teacher was an outstanding instructor

\section{Research Questions}

1. To what degree does student's attitude towards Accounting become more positive as a result of class?

2. To what degree do student's desire to consider Accounting as a major or minor as a result of class?

3. To what degree do final exam scores between Accounting classes differ?

4. To what degree does a student's learning style, aptitude, GPA, age, gender, student class year, major, marital status, ethnicity, and prior accounting academic experience interact with item 8 and 9 responses on student's satisfaction survey (Refer to Appendix)?

5. To what degree does a student's learning style, aptitude, GPA, age, gender, student class year, major, marital status, ethnicity, and prior accounting academic experience interact with final exam scores?

\section{Research Method}

\section{Sample Selection}

The subjects will consist of 108 undergraduate students at Shaw University (Raleigh, NC) composed of following sub-groups during Fall Semester of 2003:

Accounting Principles I (Morning class) 34

Accounting Principles I (Afternoon class) 25

Accounting Principles I (Evening class) 21

Federal Income Taxation (Evening class) $\quad \underline{28}$

Total $\underline{\underline{108}}$

\section{Data Collection}

During first two weeks of classes, following instruments will be distributed to determine student's individual characteristics:

1. Kolb's Learning Style Inventory

2. Demographic Information (Gender, Major, Aptitude, GPA, Age, Class, Major, Ethnicity...)

3. Pre-test of Accounting Principles

4. Modular and Comprehensive Final exam scores

\section{The Learning Styles Inventory (Refer to Appendix)}

Kolb (1976) developed 12-item self-reported Learning Styles Inventory (LSI) to assess learning styles. Short statements concerning learning situations are presented, and respondents are required to rank-order four sentence endings that correspond to the four learning styles. Kolb (1985) later refined the LSI, resulting in the LSI- 
1985 version, which incorporated some improvements (i.e., the internal consistency reliabilities).

\section{Experimental Design-Accounting Principles I Course}

Accounting Principles students will use same textbook, cover similar material, do similar homework assignments (10\%) and projects (30\%), and will be given same two modular exams (30\%) and one comprehensive final exam (30\%). The Accounting Principles I (afternoon class) conducted in a Women's detention center did not have access to textbooks due to budget problems. To compensate for lack of textbooks, SedaNotes comprised of excerpts from textbook and summary handouts were made available to all students. Textbook used was "Principles of Accounting: A Focus on Analysis and Interpretation-Eighth Edition" authored by Hillman, Kochanek, and Barsky and published by Dame Thomson Learning. The following is a sample summary of concrete, reflective, abstract and active experimentation activities and facilitator techniques used during first eleven weeks of classes.

\section{Week 1:}

As a facilitator, I try to create a learning environment where everyone respects each other and open discussion is encouraged. In order to accomplish this open learning environment, I first get acquainted with students by passing out syllabus, annual reports from two companies, a sample of financial ratio analysis of a company, and index cards on which students are instructed to complete following information and questions:

1. Name, ID\#, Major, Work experience, Hobbies, Short-term and Long-term Goals

2. Describe an Annual Report?

3. Describe Accounting?

Everyone proceeds to briefly introduce himself or herself and answers posed questions and I proceed to post selected information on board. During first week, I try real hard to memorize student's names and one related personal fact, such as a hobby or goal. After everyone is finished with their introductions, I introduce myself with a goal of connecting with them. My goals during this first week are to show students that I care about each student and that I can help them develop on a professional and personal level.

\section{Concrete and Reflective Activities:}

Students form groups and then proceed to ask them following questions:

1. Describe company discussed in your annual report?

2. Identify name of financial statements or reports?

3. Identify total assets, liabilities, and equity?

4. Define assets, liabilities, and equity?

5. Define net income?

6. Did operations and cash flow improve over last year?

7. What is worth of company?

8. Why do companies issue annual report?

9. What is an Independent Auditors Report or opinion?

10. Who audited your company?

11. What is a CPA?

12. What is stock price of company?

13. Would you recommend buying stock of company? Why?

14. What is most important to the owner of a business?

15. Identify types of ratios used to evaluate liquidity, solvency, and profitability of companies?

16. Is a current ratio of 2:1 good? 
As a facilitator, I try to actively engage students on a practical and theoretical level using a subtle approach. As students are answering aforementioned questions, I am posting their information to board that contains Accounting Equation and Net Income formulas. Theoretical concepts are covered but in a real-world dimension.

\section{Abstract and Active Experimentation Activities:}

Students are instructed to read chapter on Introduction to Accounting and to do selected exercises (usually 3-4) to be reviewed in class. One comprehensive problem is then assigned usually over weekend to be handed in for a grade. I also discuss Term Project Assignment \#1 that involves group/individual oral/written presentations of the analysis of a company's annual report due last week of semester. I recommend that students obtain annual report, describe company's operations and review financial ratios at end of week one. The following extra-credit projects are given to students:

1. visit www.ncarolinasms.org website and research stocks that class should buy and why

2. prepare summary posters of concepts discussed in class

3. tutoring classmates

4. obtain annual reports for class

\section{Week 2:}

Kolb's Learning Style Instruments (LSI) are distributed to students for completion. After LSI's are collected, handouts of my agenda are distributed describing topics to be covered and related questions with page references.

\section{Concrete and Reflective Activities:}

Students are referred to textbook or handouts that contain Income Statement, Statement of Owner's Equity, and Balance Sheet of corporation and then students are posed following information or questions listed on agenda:

1. Define Assets, Liabilities, and Equity?

2. Identify components of Owner's Equity?

3. Define Common Stock, Retained Earnings, Revenues, Expenses, and Dividends?

4. What type of company is it?

5. What is company worth?

6. What is minimum price owner(s) should sell business for to break even?

7. Identify 10 transactions for this firm and describe effect on Accounting Equation.

As students are answering aforementioned questions, I am posting their information to board that contains the Accounting Equation, Net Income, and Owner's Equity formulas. Demo problem at end of chapter is then reviewed.

\section{Abstract and Active Experimentation Activities:}

Students are then instructed to read Chapter 1 and to do selected exercises and problems. Student's progress with Term Project Assignment is discussed. The following additional extra-credit projects are given to students:

1. playing monopoly with friends and recording effect of transactions on Accounting Equation

2. visit www.ncarolinasms.org website and play stock market simulation game (see me for password)

3. visit www.startheregoplaces.com and make a report on CPA certification and careers in Accounting 


\section{Weeks 3 and 4:}

As a facilitator, I try to keep the pace of learning active and interesting. If students are listening attentively, taking notes (graded), posting information on board, working on a problem in a group or individually, my job is done. Sometimes I need to change pitch of voice, approach students, and/or distribute candy to motivate.

\section{Concrete and Reflective Activities:}

Journalizing of transactions is demonstrated by using Peachtree Accounting Software in class noting importance of chart of accounts, debit/credit concepts as well as effect on account balances in trial balance report. Students are then referred to textbook or handouts reflecting debit/credit rules, a sample chart of accounts, recording and posting of 10 sample transactions, preparation of related trial balance and financial statements. During this process, T accounts (General Ledger), General Journal, Income Statement, and Balance Sheet are created on board to help students visualize process. Following information or questions are posed to students:

1. What is a debit/credit?

2. Define chart of accounts and trial balance?

3. What account number sequence refers to assets, liabilities, and equity accounts?

4. What is increase side for Assets, Expenses, Dividends and Owner's Drawing Accounts?

5. What is increase side for Liabilities, Revenues, Common Stock and Retained Earnings Accounts?

6. Can someone volunteer to read transactions 1-10?

7. Differentiate between a General Journal and a General Ledger.

8. Can someone come to blackboard and help me record debit/credit analysis to General Journal?

9. What is purpose of PR column in General Journal?

10. Can someone else come to blackboard and help me post information to General Ledger?

11. Can a group come to blackboard and help me prepare trial balance and financial statements?

12. What is worth of business?

13. What is formula for net income?

14. What is formula for owner's equity?

15. After discussing concepts, demo problem at end of chapter is reviewed.

\section{Abstract and Active Experimentation Activities:}

Students are then instructed to read next chapter and to do selected exercises and problems. Term Project \#2 (due by Week 7) is discussed with students that involves creation of a manual or automated accounting information system of a company using data from a Comprehensive Problem in text. Following additional extracredit projects are posted:

1. playing monopoly and recording debit/credit effect of transactions in a General Journal

2. visit www.startheregoplaces.com and play business simulation game and report results

\section{Weeks 5 and 6:}

As a facilitator, I try to give each student an opportunity to receive an "A" in course so SedaNotes are distributed summarizing debit/credit rules and related transactions covered to date.

\section{Concrete and Reflective Activities:}

SedaNotes-Debit Credit Code Breaker/Rules handout are reviewed with students. Students are then referred to textbook or handouts linking to a demo problem containing partial unadjusted trial balance and additional data. Following questions listed on agenda are then posed to students: 
1. Define Prepaid Rent and Unearned Revenue.

2. Based on data, are balances of Prepaid Rent and Unearned Revenue accounts correct? Why?

3. What accounts are missing from unadjusted trial balance?

4. How can we adjust accounts and hence disclose truth to investors, creditors, and IRS?

5. Referring to SedaNotes-Debit Credit Code Breaker/Rules handout, what adjustments are necessary?

6. How much Interest Expense and Depreciation Expense should be recorded?

7. What is formula for interest and straight-line depreciation?

\section{Abstract and Active Experimentation Activities:}

Students are then instructed to read next chapter and do selected exercises and problems. Student's progress with Term Project Assignments \#1 and 2 are discussed. Following additional extra-credit projects are given to students:

1. automating assignment \#2 using Excel according to SedaNotes-Quick Books Guidelines

2. tutoring students for exam \#1

3. visit www.geocities.com/docseda and play Financial Accounting Jeopardy as a review for exam

\section{Week 7:}

Term Project Assignment \#2 is collected, a review is conducted for exam \#1, and exam \#1 is administered consisting of 40 multiple-choice questions taken from standardized test bank. Test questions are a mixture of simple, medium and hard questions that incorporate each level of Bloom's taxonomy of objectives (Knowledge, Comprehension, Application, Analysis, Synthesis, and Evaluation). I allow students to have one index card of notes during exam.

\section{Weeks 8 and 9:}

An updated version of SedaNotes-Debit Credit Code Breaker/Rules are handed out and reviewed with students. Students are then referred to textbook or handouts linking to demo problem containing worksheet and related financial statements and additional data. Following questions listed on agenda are then posed to students:

1. What is business worth?

2. What is balance of Retained Earnings as of 12/31/03 per Balance Sheet?

3. What is balance of Retained Earnings as of 12/31/03 per Worksheet or General Ledger?

4. What is major purpose of closing entries (CJEs)?

5. Referring to SedaNotes-Debit Credit Code Breaker/Rules handout, what 4 CJEs are necessary?

6. $\quad$ Can someone volunteer to post CJEs to T accounts set up on board?

7. After closing entries are posted to general ledger, which accounts have zero balance?

8. Define Post-closing trial balance (PCTB).

9. What is balance of Retained Earnings as of $12 / 31 / 03$ per PCTB?

\section{Abstract and Active Experimentation Activities:}

Students are then instructed to read next chapter and to do selected exercises and problems. Student's progress with Term Project Assignment \#1 is discussed. The following additional extra-credit projects are given to students:

1. Redo assignment \#2 (follow-up on professor's graded remarks) 


\section{Weeks 10 and 11:}

\section{Concrete and Reflective Activities:}

Journalizing typical merchandising transactions are reviewed using SedaNotes-Debit Credit Code Breaker/Rules handout. Students are then referred to textbook or handouts exhibiting worksheet and financial statements for a merchandising company. Following information or questions listed on agenda are posed to students:

2. Identify differences between income statements of service and merchandising businesses?

3. Identify components of Cost of Goods Sold (Expense)?

4. What type of accounts are Purchase Discounts and Purchase Returns and Allowances?

5. What type of accounts are Sales Discount and Sales Returns and Allowances?

6. What do terms $2 / 10, \mathrm{n} / 30$, and F.O.B. shipping point mean?

7. Define Gross Margin.

8. Identify differences between worksheets of service and merchandising businesses?

9. What is business worth?

10. What is balance of Retained Earnings as of 12/31/03 per Balance Sheet?

11. What is balance of Retained Earnings as of 12/31/03 per Worksheet or General Ledger?

12. What is major purpose of closing entries (CJEs)?

13. Referring to SedaNotes-Debit Credit Code Breaker/Rules handout, what 4 CJEs are necessary?

14. Can someone volunteer to post CJEs to T accounts set up on board?

15. After closing entries are posted to general ledger, which accounts have zero balance?

16. What is balance of Retained Earnings as of 12/31/03 per PCTB?

17. After discussing concepts, demo problem at end of chapter is reviewed.

\section{Abstract and Active Experimentation Activities:}

Students are then instructed to read next chapter and to do selected exercises and problems. Student's progress with Term Project Assignment \#1 is discussed. Following additional extra-credit projects are posted:

1. creation of a manual or automated accounting information system of merchandising company using data from a Comprehensive Problem in text

\section{Experimental Design-Federal Taxation I Course}

Federal Income Taxation students will use same textbook, cover similar material, do similar homework assignments and projects, and will be given same three tax return scenarios and one comprehensive in-class final exam. Textbook used was "Income Tax Fundamentals" authored by Whittenburg and Altus-Buller published by South-Western-Thomson Learning. The following is a summative set of the concrete, reflective, abstract, and active experimentation activities.

\section{Weeks 1-16:}

Facilitator techniques are similar to those used in previously discussed Accounting Principles section. All activities to be discussed are group based except for final exam. Students scoring an A or B on final exam will be eligible to take IRS exam near end of semester to qualify for VITA program in spring of 2004.

\section{Concrete and Reflective Activities:}

Agenda is distributed to students linking them to textbook pages or handouts exhibiting federal tax forms and related tax regulations and demo problems illustrating 1040 Components, Gross Income and Exclusions, Business Expenses, Retirement Plans, Self-Employed and Employee Expenses, Itemized deductions, Tax credits, 
Depreciation and Capital Gains and Losses. Students are then posed reflective questions (similar to prior section) concerning these tax concepts and related tax forms.

\section{Abstract and Active Experimentation Activities:}

Students are instructed to read Chapter 1-9, and to do multiple-choice questions at end of each chapter to be reviewed in class. One tax return problem from each chapter is then assigned usually over weekend to be handed in for grade. Tax returns may be prepared manually or using tax software. Each student is given copy of H\&R Block's Tax Cut Software to be used solely for educational purposes. Student evaluation was base on two modular mini-tax returns (30\%), one comprehensive tax return, one comprehensive in-class final exam (30\%), consisting of 40 multiple-choice questions from standardized test bank covering Chapters 1-9, and active classroom attendance and participation (10\%). All tax return problems were selected from textbook. Students were allowed one index card of notes to be used during in-class individual final exam.

\section{Evaluation}

The research questions/hypotheses will be evaluated using following measures:

1. ANOVA statistical tests at .01 significance levels will be used to determine whether final exam scores between groups of Accounting Principles classes differed significantly

2. Specific questions on Student's Satisfaction Survey (Likert Scale) will be used to determine whether student's attitude towards Accounting become more positive and whether student's desired Accounting as major/minor as a result of class

3. Multiple Regression Correlation Analysis will also be used to determine whether a student's learning style, aptitude, GPA, age, gender, student class year, major, marital status, ethnicity, and prior accounting academic experience interacted with item 8 and 9 responses on student's satisfaction survey

4. Multiple Regression Statistical Correlation Analysis will also be used to determine whether a student's learning style, aptitude, GPA, age, gender, student class year, major, marital status, ethnicity, and prior accounting academic experience interacted with final exam scores

\section{Results}

The following is a summary of selected demographic data:

Variable Descriptions Frequency $\%$ Gender:

Female (ACC)

Male (ACC)

Female (Tax)

Male (Tax)

\begin{tabular}{|c|c|}
\hline 61 & 76 \\
\hline$\underline{19}$ & $\underline{24}$ \\
\hline$\underline{80}$ & $\underline{100}$ \\
\hline$\overline{20}$ & 71 \\
\hline$\underline{8}$ & $\underline{29}$ \\
\hline$\underline{\underline{28}}$ & $\underline{\underline{100}}$ \\
\hline
\end{tabular}

Age:

19-22 (ACC)

Total $\underline{\underline{108}}$

22-30 (ACC)

35

44

31-40 (ACC)

1620

41-54 (ACC)

$16 \quad 20$

$19-22(\operatorname{Tax})$

22-30 (Tax))

$\frac{13}{80}$

$\underline{16}$

31-40 (Tax)

$\underline{\underline{80}}$

$\underline{\underline{100}}$

41-54 (Tax)

\begin{tabular}{rr}
3 & 11 \\
16 & 57 \\
$\underline{6}$ & $\underline{21}$ \\
$\underline{\underline{\underline{28}}}$ & $\underline{\underline{100}}$ \\
\hline
\end{tabular}

Total $\underline{\underline{108}}$ 


\section{Ethnic Background:}

African American (ACC)

Caucasian (ACC)

Hispanic (ACC)

African American (Tax)

Class:

Sophomore (ACC)

Junior (ACC)

Senior (ACC)

Sophomore (Tax)

Junior (Tax)

Senior (Tax)

81

18

\begin{tabular}{rr}
14 & 18 \\
\hline 80 & $\underline{100}$ \\
\hline$\underline{100}$
\end{tabular}

$\underline{\underline{\underline{28}}} \underline{\underline{\underline{100}}}$

Total $\underline{\underline{108}}$

25

$48 \quad 60$

7 $\quad 9$

$\underline{\underline{80}} \quad \underline{\underline{100}}$

4

932

$\underline{15}$

$\underline{\underline{28}} \underline{\underline{100}}$

Learning Style:

Diverger (ACC)

Accommodator (ACC)

Converger (ACC)

Total $\underline{\underline{108}}$

Variable Descriptions

Assimilator (ACC)

Diverger (Tax)

Accommodator (Tax)

Assimilator (Tax)

Major:

Accounting (ACC)

Business Administration (ACC)

Business Management (ACC)

CIS (ACC)

Criminal Justice (ACC)

International Business/Relations (ACC)

Mathematics (ACC)

Psychology (ACC)

Public Administration (ACC)

Sociology (ACC)

Undeclared (ACC)

Accounting (Tax)

Business Administration (Tax)

Business Management (Tax)

HS Bookkeeping:

$30 \quad 38$

$13-16$

34

\begin{tabular}{|c|c|c|}
\hline & Frequency & $\%$ \\
\hline & 34 & 43 \\
\hline & $\underline{80}$ & 100 \\
\hline & 17 & 61 \\
\hline & 3 & 10 \\
\hline & 8 & $\underline{29}$ \\
\hline & $\underline{\underline{28}}$ & 100 \\
\hline Total & $\underline{\underline{108}}$ & 100 \\
\hline
\end{tabular}

\begin{tabular}{|c|c|c|}
\hline & & \\
\hline & & \\
\hline & 24 & 30 \\
\hline & 19 & 24 \\
\hline & 12 & 15 \\
\hline & 3 & 4 \\
\hline & 3 & 4 \\
\hline & 1 & 1 \\
\hline & 1 & 1 \\
\hline & 2 & 2 \\
\hline & 6 & 8 \\
\hline & 1 & $\underline{1}$ \\
\hline & $\overline{\underline{80}}$ & $\underline{10 \overline{0}}$ \\
\hline & $\overline{6}$ & $\overline{21}$ \\
\hline & 16 & 58 \\
\hline & $\underline{6}$ & $\underline{21}$ \\
\hline & $\underline{2 \overline{8}}$ & $\underline{100}$ \\
\hline Total & $\underline{\underline{108}}$ & \\
\hline & 20 & 25 \\
\hline & $\underline{60}$ & 75 \\
\hline Total & $\underline{\underline{80}}$ & $\underline{\underline{100}}$ \\
\hline
\end{tabular}




\section{Previous Enrolled in Accounting Principles Course:}

Yes (ACC)

No (ACC)

$\begin{array}{rr}15 & 19 \\ \text { Total } \quad \underline{65} & \underline{81} \\ \underline{80} & \underline{\underline{100}}\end{array}$

The summary demographic data listed above shows that the average student taking Accounting Principles possessed following characteristics: 1)Gender: Female (76\%); 2)Age: 19-22 (44\%); 3)Ethnicity: African American (81\%); 4)Class: Junior (60\%); 5) Learning style: Assimilators (43\%); 6)Major: Business Administration (30\%); 7) did not take Accounting in High School (75\%) and 8) did not enroll in Accounting Principles class in prior semesters.

The summary demographic data listed above shows that the average student taking Federal Income Tax possessed following characteristics: 1)Gender: Female (71\%); 2)Age: 31-40 (57\%); 3)Ethnicity: African American $(100 \%)$; 4)Class: Senior (54\%); 5)Learning style: Divergers (61\%); and 6)Major: Business Administration (58\%).

\section{Findings Related to Research Questions/Hypotheses}

\section{Research Question one:}

To what degree does student's attitude towards Accounting become more positive as result of class?

This question related specifically to question 8 on student satisfaction survey (see appendix). Results below show that $90 \%$ of students agreed that their attitude towards Accounting has become more positive as a result of my class hence the null hypothesis is rejected.

\begin{tabular}{lccc} 
Variable Descriptions & Frequency & \% & Cum.\% \\
\hline Strongly Agree & 58 & 54 & 54 \\
Agree & 39 & 36 & 90 \\
No Opinion & 5 & 5 & 95 \\
Disagree & 4 & 4 & 99 \\
Strongly Disagree & 1 & 1 & 100 \\
N/A & Total $\underline{1} \underline{\underline{08}}$ & 1 &
\end{tabular}

\section{Research Question two:}

To what degree do student's desire to consider Accounting as a major or minor as a result of class?

This question related to question 9 on student satisfaction survey (see appendix). The results below show that $47 \%$ of students agreed that they are considering Accounting as a major or minor as a result of my class hence null hypothesis is rejected. If the 24 student selections of No Opinions and N/A are ignored, adjusted cumulative percentage of students (based on adjusted population of 84 students) considering Accounting as a major or minor as a result of my class would increase to $61 \%$. This adjustment is real since 22 graduating seniors are included in student research population. 


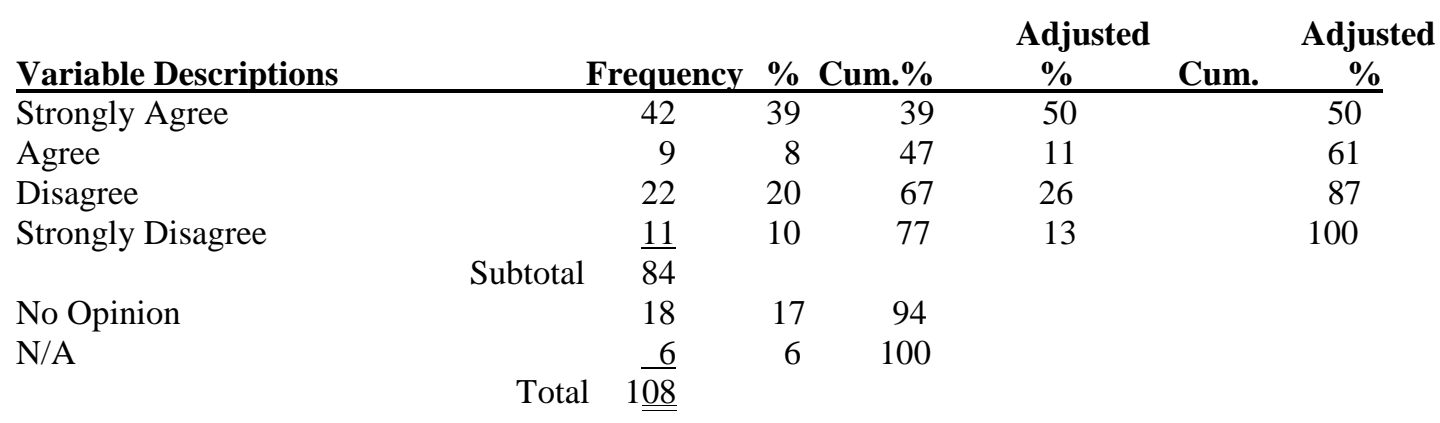

\section{Research Question three:}

To what degree do final exam scores between Accounting classes differ?

Since the computed $\mathrm{F}$ value is greater than $\mathrm{F}$ critical value at P-value of .0000461 , the ANOVA results below show that there is a significant difference between the final exam scores of the Accounting Principles classes and hence the null hypothesis is rejected. In fact, results show that the Principles of Accounting afternoon section conducted in a women's detention center, where students did not have access to books, significantly outperformed other related sections on final exam with a rounded mean average of $84 \%$.

\section{Summary}

\begin{tabular}{lcccc}
\hline Groups & Count & Sum & Average & Variance \\
\hline Day & 31 & 2342 & 75.54839 & 92.85591 \\
Evening & 22 & 1787 & 81.22727 & 48.18398 \\
Afternoon & 27 & 2267 & 83.96296 & 40.49858 \\
\hline
\end{tabular}

\begin{tabular}{|c|c|c|c|c|c|c|}
\hline Source of Variation & $S S$ & $d f$ & $M S$ & $F$ & P-value & $F$ crit \\
\hline Between Groups & 1071.296 & 2 & 535.648 & 8.503218 & 0.000461 & 3.11536 \\
\hline Within Groups & 4850.504 & 77 & 62.99356 & & & \\
\hline Total & 5921.8 & 79 & & & & \\
\hline
\end{tabular}

\section{Research Question four:}

To what degree does student's learning style, aptitude, GPA, age, gender, class year, major, marital status, ethnicity, and prior accounting academic experience interact with item 8 and 9 responses on student's satisfaction survey?

Results below show that demographic variables affected by these questions were very similar and hence null hypothesis is rejected. Both items 8 and 9 interacted significantly positive with learning style $(+.25, .15$ correlation factors), students previously enrolled in Accounting Principles (+.11, .12 correlation factors), students who ranked in top of class and received high HS grades $(+.22, .07$ correlation factors), and students with high cumulative GPAs (+.20, .09 correlation factors). In other words, students with Diverger Learning Styles, as well as, student repeaters and highly ranked students had a more positive attitude to Accounting and are considering Accounting as a major or minor. Supporting research by Kolb (1985) indicates that accountants are usually divergers. 


\section{Regression Correlation Analysis}

Learning Style

Previously Enrolled in Accounting Principles

\# of clock hrs attended in previous semesters

Previous Semester enrolled in Accounting I

Major

Age

Class year

Took High School Bookkeeping Class

Grade received in Bookkeeping Class

Gender

Marital Status

Ethnicity

Rank in HS

SAT Score

Cumulative GPA
Item \#9

0.153253

0.120607

$-0.30777$

$-0.42602$

0.050627

$-0.12225$

0.00708

0.13662

0.376645

$-0.066$

$-0.18834$

0.099445

0.065496

$-0.10997$

0.093478
Item \#8

0.249974

0.109191

$-0.11368$

$-0.22206$

$-0.00582$

$-0.05565$

$-0.03514$

$-0.10821$

0.318754

0.166336

$-0.05537$

$-0.04379$

0.216416

$-0.09756$

0.203292

\section{Research Question five:}

To what degree does a student's learning style, aptitude, GPA, age, gender, student class year, major, marital status, ethnicity, and prior accounting academic experience interact with final exam scores?

The results below show that the demographic variables age, with a + correlation factor of .12 , and prior enrollment in Accounting Principles classes, with a + correlation factor of .30 , significantly interacted with final exam scores of the Accounting Principles classes and hence the null hypothesis is rejected. In other words, the older and more mature students as well as the students who are repeating Accounting Principles I class did better on final exam. Furthermore, the closer to Fall of 2003 that student repeaters failed or dropped out of prior Accounting Principles class, with a + correlation factor of .43 , the better the person performed on final exam. The number of repeaters amounted to 15 and they were evenly dispersed among three Accounting classes and hence should not diminish significance of ANOVA results previously mentioned.

\begin{tabular}{lc}
\hline Regression Correlation Analysis/Final Exam Score & \\
\hline Learning Style & -0.13972 \\
Previously Enrolled in Accounting Principles Course & 0.299592 \\
\# of clock hours attended in a prior semester & 0.329806 \\
Enrolled in Accounting Principles during previous Semester or later & 0.430083 \\
Major & -0.02184 \\
Age & 0.12199 \\
Class & -0.16617 \\
Took a High School Bookkeeping Class & -0.04297 \\
Grade received in HS Bookkeeping Class & -0.76095 \\
Gender & 0.005329 \\
Marital Status & 0.016285 \\
Regression Correlation Analysis/Final Exam Score & \\
Ethnicity & -0.15702 \\
Rank in High School & -0.45347 \\
SAT Score & -0.38527 \\
Cumulative GPA & -0.51856 \\
\hline
\end{tabular}




\section{Student Comments:}

Results show that students were very satisfied with my course presentation, enthusiasm, grading system, and overall teaching style. My average score of student satisfaction was $97 \%$ on related student survey items 1-7, and 10 (see Appendix). Apparently, these students appreciated all the little things that I, as a facilitator, did to help them learn. As a facilitator, my mission to simultaneously care about them and to challenge them as active individual and group learners with meaningful real-world experiences worked. The following is a summary of student comments for your review:

\section{\# $\quad$ Student Comments}

Freq

1. Enjoyed real world applications 5

2.. $\quad$ Enjoyed Professor's enthusiasm, expertise, passion for teaching, teaching style... 38

3. Realized importance of Accounting in world of business and in life. 5

4. Professor takes time to explain content thoroughly and is always willing to help. 5

5. Enjoyed Hands-on learning experiences and group projects. 4

6. Professor made Accounting interesting and fun. 4

7. Very fair grading and testing procedure. 3

8. Professor makes Accounting easy to understand. 2

9. Appreciated Sedanotes 3

10. Professor showed excellent interaction with students 1

11. Great class, "fun" class, great professor 16

12. Professor has made me more enthusiastic about Accounting and my future. 1

13. Enjoyed learning about business, money, and the language of business (Accounting). 11

14. Course was excellent due to teacher. 1

15. I really enjoyed course and I'm considering a minor in Accounting. 1

16. My job performance has improved due to this class. 1

17. Constant student involvement created by professor was great. 3

18. I appreciated candy. $\quad 1$

19. Professor's use of life experiences were great. 1

20. Professor motivated me to learn by his patient explanation of content. 6

21. I loved this course. 1

22. Enjoyed learning how to prepare tax returns. 6

23. Tax software provided by teacher was very helpful. 1

24. Course provided a well-rounded education in business. 3

25. Enjoyed review of multiple choice questions. 1

26. Enjoyed learning all the tax laws and related tax forms. 3

27. Enjoyed take-home exams involving comprehensive tax problems. 1

28. Need to create an Advanced Federal Income Tax course. 8

29. Need internship program. 1

30. Class should be taken in a computer lab. 2

31. Should have taken advantage of free tutoring services 1

32. Slow down pace of class. 2

33. Need integration of Accounting software such as, Peachtree and QuickBooks. 6

34. Need more time to work on computer projects 2

35. Class size was too large. 1

36. Building and classroom needs to be technologically updated. 1

37. Need books and more board space in women's detention center. 10

38. Need tutoring services in women's detention center. 


\section{Conclusion}

I've shown that the integration of meaningful group learning experiences in Principles of Accounting and Tax classes can be effectively used to positively change student's attitude towards Accounting and to promote Accounting as a major or minor at undergraduate level. Teachers should try using Baker, Simon, and Bazelli's (1985) Instructional Design for Accounting based on Kolb's Experiential Group Learning Model, since multiple teaching strategies appealing to multiple student learning styles can result in a win-win situation for everyone involved.

In the future, this study could be replicated in Accounting, as well as, other subjects due to the universality of Kolb's Experiential Group Learning Model. Perhaps teachers could pre-assign students to homogeneous and heterogeneous groups to further test the efficacy of the model. Anyone interested in obtaining additional information and Appendix materials related to this study should e-mail me at docseda@nc.rr.com.

\section{References}

1. Accounting Education Change Commission (AECC). 1990. Objectives of education for accountants: Position statement number one. Issues in Accounting Education (fall): 307-312.

2. Astin, A. W. 1993. What matters in college? Implications for cooperative learning of a new national study. Cooperative Learning and College Teaching 3(3): 2-8.

3. Baker, R.E., Simon, J.R., \& Bizelli, F.P. 1987. Selecting instructional design for introductory accounting based on the experiential learning model. Journal of Accounting Education, Fall: 207-226.

4. Barsky, N., Catanach, A.H., \& Kozlowski, B.M. 2003. Creating Strategic Responses to Critical Risks Facing Accounting Education. Issues in Accounting Education, November: 445-462.

5. Bloom, B. S. 1971. Mastery Learning: Theory and Practice. New York, NY: Holt, Rinehart, and Winston

6. Collins, J. H., \& Milliron, V. C. (1987). A measure of professional accountants' learning style. Issues in Accounting Education, fall, 193-206.

7. Cottell, P., and B. Millis. 1993. Cooperative learning structures in the instruction of accounting. Issues in Accounting Education 8 (spring): 40-59.

8. Cottell, P., and B. Millis. 1994. Cooperative Learning and Accounting. Cincinnati, OH: South-Western Publishing Co.

9. Drew, F., \& Ottewell, R. (1998). Languages in undergraduate business education: A clash of learning styles. Studies in Higher Education, 23(3), 297-305.

10. Fiechtner, S. B., and E. A. Davis. 1992. Why some groups fail: A survey of students' experiences with learning groups. In Collaborative Learning: A Sourcebook for Higher Education, University Park, PA: National Center on Postsecondary Teaching, Learning, and Assessment.

11. Fraser, S. C., E. Diener, A. Beaman, and R. T. Kelem. 1977. Two, three, or four heads are better than one: Modification of college performance by peer monitoring. Journal of Educational Psychology 69: 101-108

12. Hite, P. 1996. An experimental study of the effectiveness of group exams in an individual income tax class. Issues in Accounting Education, Vol.11, No.1:61-63.

13. King, A. 1992. Promoting active learning and collaborative learning in business administration classes. Critical Thinking, Interactive Learning and Technology: Reaching for Excellence in Business Education. Arthur Andersen Foundation: 158-173.

14. Kolb, D. A. 1976. Learning Style Inventory: Technical manual. Boston: McBer. Learning and development. Englewood Cliffs: Prentice-Hall.

15. Kolb, D. A. 1985. The Learning Style Inventory: Technical manual. Boston: McBer.

16. Loo, R. 2002. A Meta-Analytic Examination of Kolb's Learning Style Preferences among Business majors. Journal of Education for Business: p.252-5.

17. McKeachie, W. J., P. R. Pintrich, Y. G. Lin, and D. A. Smith. 1987. Teaching and Learning in College Classroom: A Review of Literature. Ann Arbor, MI: National Center for Research to Improve Postsecondary Teaching and Learning.

18. Ravenscroft, S. P., F. A. Buckless, G. B. McCombs, and G. J. Zucherman. 1993. Incentives in student team learning: An experiment in cooperative group learning. 
19. Stuart, J., and R. J. Rutherford1976. Medical student concentration during lectures. The Lancet 10:514-516.

Notes 